\title{
Measurement of spatial agglomeration level and the characteristics of space-time evolution of China's construction industry
}

\author{
Likun Zhao, Junsen Tian*, and Yanqi Liu \\ School of Civil Engineering, North China University of Technology, Beijing100144, China
}

\begin{abstract}
Industrial agglomeration is the most prominent performance in current economic activities. In this study, the output value of construction engineering is taken as the core index. The relevant data of 31 provinces and cities in China from 2008 to 2019 are selected. The spatial agglomeration level and spatial and temporal evolution characteristics of Chinese construction industry in 10 years are studied using the Gini coefficient and the strongest gravity model. Results show that the spatial agglomeration level of China's construction industry has been increasing annually, and the industry has experienced the development process of "disequilibrium to gradual equilibrium." (1) The distribution of construction industry in 31 provinces and cities of China is characterized by spatial imbalance. (2) The agglomeration areas of high-high construction industrial elements are mainly concentrated in Beijing-Tianjin-Hebei and Yangtze River Delta urban agglomeration. Low-low industrial element agglomeration areas are concentrated in the urban agglomeration of southwest China. (3) The center of gravity of the spatial agglomeration of the elements of China's construction industry is moving from the east to the central and western regions and gradually tends to be balanced.
\end{abstract}

\section{Introduction}

Industrial agglomeration is the long-term convergence process of capital elements in the space scope and is the most prominent spatial characteristic of economic activities. In the 19th century, Marshall began to pay attention to the economic phenomenon of industrial agglomeration and proposed two important concepts of "internal economy" and "external economy" [9]. The current research results mainly focus on the formation and impact mechanism of industrial agglomeration ${ }^{[1,2]}$, industrial agglomeration and efficiency ${ }^{[3,4]}$, industrial agglomeration and innovation ${ }^{[5,6]}$, and industrial agglomeration and evolution ${ }^{[7,8]}$.

According to Krugman's (2000) new economic geography theory, close spatial economic connection is an important reason for the formation of industrial agglomeration ${ }^{[10]}$. Wang et al. (2018) used location entropy index and dynamic spatial panel model to empirically analyze the pattern and influence mechanism of manufacturing industry and industrial agglomeration efficiency respectively ${ }^{[1-13]}$. On the basis of the theory of enterprise heterogeneity and related viewpoints introduced by Greenaway et al. ${ }^{[15-19]}$, Zhao (2019) ${ }^{[14]}$

\footnotetext{
*Corresponding author: 1412026763@qq.com
} 
analyzed the specific mechanism of industrial agglomeration affecting industrial efficiency through the degree of opening to the outside world. Sultan (2017) and Zhao et al. (2020) discussed the influence of industrial agglomeration on the regional innovation through GMM system and Cobb-Douglas production function ${ }^{[20-21]}$. Chen et al. (2018) used the gravity model to analyze the geographical spatial distribution characteristics and spatial agglomeration degree of agriculture and animal husbandry in Gansu Province and manufacturing industry in Yangtze River Delta ${ }^{[22-24]}$. He (2006) and Pan et al. (2011) ${ }^{[25-27]}$ studied the agglomeration of Chinese manufacturing industry by EG index, Gini coefficient, and SP index. They found that the entire Chinese manufacturing industry shows the trend of agglomeration before diffusion. By using location entropy index and global Moran's I method, Yi (2020) measured the evolution trend of spatial agglomeration level and spatial pattern of high-tech industries in China from the viewpoints of timing and space ${ }^{[28]}$. Su (2018) used the regional Gini coefficient and spatial autocorrelation to measure the geospatial agglomeration pattern and evolution of Jiangsu's manufacturing industry from 2001 to 2016 [29].

Some scholars have believed that regional development differences exist in the construction industry, and the industrial agglomeration phenomenon common in the industry and the tertiary industry will not occur in the construction industry ${ }^{[30]}$. However, Liu et al. (2015) used the time series multi-index model to measure the development level of the construction industry. Their results showed that the spillover effect of the construction industry in Beijing, Tianjin, the eastern coast, and the southern coast is obvious, and the magnitude of the gradient change between regions differs ${ }^{[31-32]}$. Ma (2018) used social network analysis to find that industrial agglomeration affects of collaborative innovation in the construction industry alliance in the Beijing-Tianjin-Hebei region ${ }^{[33]}$. From the perspective of spatial correlation, Bu (2019), Yang (2018), and Zhang et al. (2010) revealed that the development of construction industry between regions generally shows a significant correlation by using spatial measurement method, and its development level is from east to west and shows a ladder distribution from fast to slow ${ }^{[34-36]}$. The abovementioned research conclusions confirm that this difference must also have a certain relationship with the geographical spatial location due to the linkage of economic development between China's adjacent regions and population mobility.

In the current Internet ${ }^{+}$era, the popularization of big data has provided unprecedented convenience for the rise of the construction industry. However, the popularity of big data has brought information asymmetry and spillover effects to the construction industry, and this situation has led to the continuous subdivision of the construction industry in spatial distribution and regional aggregation. In this context, 31 provinces, cities, and autonomous regions (excluding Hong Kong, Macao, and Taiwan) in mainland China are selected as the research objects. The spatial and temporal pattern and industrial agglomeration evolution characteristics of Chinese construction industry development are comprehensively depicted and displayed using the maximum gravity model, location quotient index, and spatial Gini coefficient to explore the overall extension of Chinese construction industry pattern.

\section{Research methods}

\subsection{Gravity model}

The gravity model combines dual characteristics of spatial and attribute data and can accurately measure the spatial connection strength of the construction industry index, as shown in Equation (1). 


$$
Y_{\mathrm{mn}}=K \frac{f_{m} f_{n}}{d_{m n}^{\mathrm{b}}} \square \mathrm{m} \neq \mathrm{n} \square \mathrm{m} \square \mathrm{n}=1 \ldots 31 \square,
$$

where $Y_{m n}$ is the gravitational strength of the construction industry between provincial $\mathrm{m}$ and $\mathrm{n}, K$ is the correction coefficient.

The gravity of the development of the construction industry in different provinces is asymmetric. Thus, $K=f_{m} /\left(f_{m}+f_{n}\right)$ is used as the correction coefficient of the gravity strength of $m$ to $n$ in the province. $f_{m}$ and $f_{n}$ are the construction industry development indexes of the cities $m$ and $n$-the output value of construction projects. The total output value of construction projects in the period of 2008-2019 accounted for more than $85 \%$ of the total source of total output value of the construction industry. Therefore, this indicator can objectively reflect the development status of the construction industry in each province. The data come from the National Database of the National Bureau of Statistics. $d_{m n}$ is the diameter distance of cities $m$ to $n$. The longitude and latitude of 31 provinces (municipalities and autonomous regions) are obtained through ArcGIS software, and the geographical distance matrix between different provinces and cities is sorted and calculated. $\mathrm{b}$ is the distance friction coefficient, assigned a value of 1 , and used to control the influence strength of the spatial distance on the gravitational strength.

The gravitational strength of $m(m=1 \ldots 31)$ to the 30 other provinces (cities and autonomous regions) is calculated by the gravity model. The largest of them $Y_{\text {mnmaxm }}=\left\{Y_{m 1} Y_{m 2} \ldots Y_{m n}\right\}$ is selected as the gravitational strength of the construction industry in $m$ province $(m=1 \ldots 31)$, and the maximum gravitational strength matrix $\left\{Y_{\operatorname{mn} m a x}\right\}$ is finally obtained.

\subsection{Social network analysis}

The network density reflects the closeness of the association between the provinces of the construction industry, as shown in Equation (2).

$$
D=L / N(N-1) \text {, }
$$

where $D$ is the annual node construction industry network density; $L$ is the number of relationships actually existing in the construction network structure of the provincial industry; $N$ is the number of provinces, and the value is 31 .

Network relevance. The robustness of network structure of construction industry development is proportional to the degree of network correlation, as shown in Equation (3).

$$
C=1-U /(N(N-1) / 2),
$$

where $C$ is the annual node construction industry network relevance and $U$ is the logarithm of the unreachable provinces in the construction industry development network structure

Network efficiency. When the number of connections between any two provinces is greater, the network efficiency is lower and the development of the construction industry between provinces is more closely related, as shown in Equation (4).

$$
E=1-M / \max M \text {, }
$$

where $E$ is the annual node construction industry network correlation degree, $M$ is the redundant line number, and $\max M$ is the theoretical maximum redundant line number.

The degree of point degree center represents the total number of maximum gravity connection lines (including degree of exit and degree of entry) between a province and other provinces directly connected. When the degree of point degree center is greater, the relationship between the construction industry development of the province and surrounding provinces is closer, as shown in Equation (5). 


$$
F_{i}=\sum_{j=1}^{i} n_{i j}(i \neq j),
$$

where $\mathrm{Fi}$ is the point degree center of provincial domain $\mathrm{i}, \mathrm{Nij}$ is the total number of maximum gravitational coupling lines directly connected to provincial domain $i$ and provincial domain $j$, and $i$ is the number of provincial domains directly connected to provincial domain $i$.

Proximity to centrality means the sum of the shortest geographical distance between a province and its directly connected provinces. When the proximity to centrality is greater, the development of the construction industry in the province and the surrounding provinces is closer, as shown in Equation (6).

$$
G_{\mathrm{i}}=\sum_{j=1}^{m} d_{i j}(i \neq j),
$$

where Gi is the centrality of provincial area $\mathrm{i}$, dij is the shortest geographic distance when provincial area $i$ is directly connected with provincial area $j$, and $m$ is the number of provincial areas directly connected with provincial area i.

\subsection{Spatial Gini coefficient}

The spatial Gini coefficient, which was proposed by Krugman in 1991, is an index to measure the degree of industrial spatial agglomeration. The value range is between 0 and 1 . When the Gini coefficient is closer to 0 , the development of the construction industry is more balanced; conversely, it is more unbalanced, as shown in Equation (7).

$$
G_{\mathrm{i}}=1-1 / N W_{N}{ }^{\left(2 \sum_{i=1}^{N} W_{\mathrm{i}}-W_{N}\right)},
$$

where $G, N$, and $W$ represent the Gini coefficient of the construction industry space, the proportion of provinces or years, and the total output value of construction projects, respectively.

\subsection{Moran's I index}

The global spatial autocorrelation coefficient can examine the spatial agglomeration of the construction industry as a whole by considering the similarity of the observation values of the construction industry of spatially adjacent regional units (Yang \& Qian et al., 2017). This coefficient is shown in Equation (8).

$$
I=\frac{n \sum_{i=1}^{n} \sum_{j=1}^{n} w_{i j}\left(x_{i}-\bar{x}\right)\left(x_{j}-\bar{x}\right)}{\sum_{i=1}^{n} \sum_{j=1}^{n} w_{i j} \sum_{i=1}^{n}\left(x_{i}-\bar{x}\right)},
$$

where I, $\mathrm{n}, X_{i}, \bar{x}$, and $w_{i j}$ represent the values of the Moran's I index, the number of studied subjects, spatial observations, mean, and the spatial weights, which represent the potential interactions between the spatial units under the established significant level conditions. If the Moran's I index is greater than 0 , then the correlation is spatial positive and a potential dependence exists between the units, which show the aggregation spatial distribution. Conversely, the Moran's I index of less than 0 indicates a negative correlation of space, and the discrete distribution is presented between the entities of space units. If the Moran's I index is equal to 0 , then the spatial unit entities show the characteristics of random distribution. Among them, a greater absolute value of the Moran's I index corresponds to a greater correlation of the spatial distribution. 


\section{Analysis on the regional spatial correlation pattern of China's construction industry development}

\subsection{Characteristics of regional connections in China's construction industry}

A complex network based on the gravity model is constructed through the relevant data of China's construction industry from 2008 to 2019. The spatial correlation pattern of China's construction industry development and the regional correlation characteristics of the construction industry are also analyzed.

The analysis shows that China's construction industry exhibits a certain state of industrial agglomeration at each time node. The industrial agglomeration center gradually expanded from the four cities of Zhejiang, Shaanxi, Beijing, and Sichuan in 2008 to Hebei, Chongqing, Zhejiang, Jiangsu, Hunan, Shanghai, and other regions. The spatial agglomeration of China's construction industry gradually strengthens.

From the perspective of spatial distribution, Beijing, Shaanxi, Zhejiang, and Hebei are the four regions with the strongest radiation capabilities in China's construction industry. With the gradual deconstruction of Beijing's non-capital function and the strengthening of Beijing-Tianjin-Hebei integration, Hebei gradually replaced Beijing as the construction industry agglomeration center. The construction output value of Jiangsu Province has ranked first in the country in the past 10 years (Zhao, 2020). This situation has stabilized its construction industry agglomeration center position. From the development trend, China's construction industry gradually presents a multi-location agglomeration development pattern. The radiation effects of regional construction industry centers, such as Beijing, Shaanxi, Zhejiang, and Hebei, have gradually weakened. Thus, Guangdong, Jiangsu, and other places have continuously enhanced their radiation capabilities to the surrounding areas. The coastal area in southeastern China is expected to become the largest construction industry agglomeration center in China.

In terms of cross-provincial agglomeration of China's construction industry, Tianjin, Henan, and Guangxi provinces have performed well. However, the construction industry cluster has not yet been formed due to the geographical proximity between the three places and Beijing, Zhejiang, and Guangdong. In general, the phenomenon in which the radiation effect of adjacent geographical location construction industry is weakening each other is gradually decreasing. This situation indirectly reflects the initial formation of the regional agglomeration development pattern of Chinese construction industry.

\subsection{Analysis of spatial structure characteristics and association relationship of China's construction industry}

This section analyzes the spatial structure characteristics and relationship patterns of the development of China's construction industry in 2008-2019 from the local and overall levels through social network analysis methods.

Analysis of overall spatial network structure characteristics. A network co-occurrence matrix is constructed on the basis of the maximum gravity strength matrix $\{Y \operatorname{mnmax}\}$ of the construction industry development in 31 provinces (municipalities and autonomous regions) in China. Through the Gephi visualization tool, the evolution process of the associated structure of the Chinese construction industry development network in the years of 2008 and 2019 is depicted, as shown in Figure 2. 

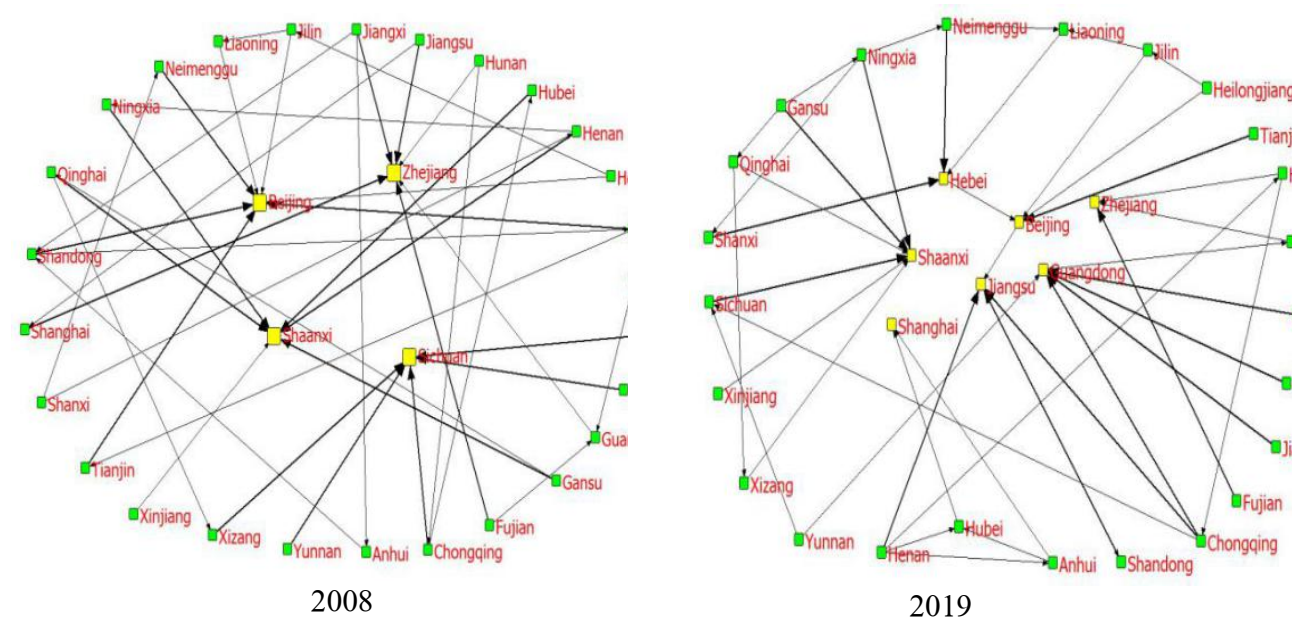

Fig. 1. Evolution process of the related structure of China's construction industry development network.

As shown in Figure 1, a certain correlation exists in the development of the construction industry among Chinese provinces. Among them, Beijing, Shaanxi, Zhejiang, and Chongqing have the strongest correlation strength. This conclusion is consistent with the abovementioned analysis of the connection strength. The development network structure of China's construction industry is gradually clear, and the characteristics of spatial agglomeration are obvious. This section introduces indicators such as network density, network relevance, and network efficiency to quantitatively analyze the spatial network relevance, as shown in Table 1, for further grasping the overall network characteristics of China's construction industry development:

Table 1. Characteristics of the overall spatial network structure of China's construction industry from 2008 to 2019.

\begin{tabular}{ccccc}
\hline Year & Network Density & $\begin{array}{c}\text { Network } \\
\text { Relevance }\end{array}$ & $\begin{array}{c}\text { Network } \\
\text { Efficiency }\end{array}$ & $\begin{array}{c}\text { Network } \\
\text { Hierarchy }\end{array}$ \\
\hline 2008 & 0.1075 & 0.8289 & 0.0161 & 0.2134 \\
2009 & 0.1085 & 0.8351 & 0.0158 & 0.2018 \\
2010 & 0.1098 & 0.8352 & 0.0132 & 0.1856 \\
2012 & 0.1135 & 0.8352 & 0.0110 & 0.1553 \\
2013 & 0.1172 & 0.8453 & 0.0103 & 0.1553 \\
2014 & 01198 & 0.8566 & 0.0219 & 0.2586 \\
2015 & 0.1358 & 0.8663 & 0.0158 & 0.2352 \\
2016 & 0.1365 & 0.8666 & 0.0096 & 0.1883 \\
2017 & 0.1473 & 0.8780 & 0.0083 & 0.1456 \\
2018 & 0.1473 & 0.8832 & 0.0056 & 0.0985 \\
2019 & 0.1475 & 0.8854 & 0.0050 & 0.0975 \\
\hline
\end{tabular}

The analysis in Table 1 shows that

The network density and network association maintain a steady growth trend, and the association relationship has remained above 0.82 . Therefore, China's construction industry has close inter-provincial exchanges and cooperation. The overall spatial association and concentration are gradually strengthening. The spatial correlation of the construction industry has transformed from one-way connection to two-way interaction, and the spatial correlation and spillover effects are obvious. The development of the Chinese construction industry has been further strengthened. 
The network level and network efficiency are generally low, and they continue to decline. Therefore, the hierarchical structural differentiation among provinces of China's construction industry is not obvious. The asymmetry in the network association structure is reduced. Interprovincial two-way and multi-directional network relationship is gradually formed, and spatial association structure tends to complicate.

The analysis of Figure 2 and Table 1 indicates that regions, such as Jiangsu, Hebei, Zhejiang, and Shaanxi, have broken through geographical boundaries in the past 10 years. Through long-distance inter-provincial cooperation, strong provincial relations have been generated, and the spatial structure has gradually stabilized. This conclusion is consistent with the increasing trend of industrial extroversion in Chinese construction enterprises, which have performed construction production and management activities across provinces according to the relevant data of China Construction Statistical Yearbook.

Among Beijing, Tianjin, and Hebei, Tianjin has a solid manufacturing foundation, which has effectively promoted the optimization and upgrading of construction material processing enterprises around Hebei Province. Through the fine division of labor across the three regions of Beijing, Tianjin, and Hebei and industrial transfer, a stable urban agglomeration ecosystem has been achieved.

At the same time, the accessibility of transportation is increasing with the country's policy tendency toward the central and western regions. Developed and slow-developing regions tend to strengthen economic activities. In summary, the spatial network structure of China's construction industry development is clear. Its spatial network association gradually changes from one-way to two-way and multi-directional, and its structure becomes increasingly complex and steady.

Structural characteristics of local spatial networks. By introducing point-degree centrality and near-centrality, the characteristics of individual space network structure in the development of China's construction industry are analyzed.

The analysis shows that the degree centrality of the Chinese provinces as a whole shows an upward trend, but the increase is relatively small. Among them, Beijing, Shaanxi, Sichuan, Zhejiang, Guangdong, and Shanghai have always been at the forefront, and their construction industry development level is also the highest. The values of the degree centrality in Tianjin, Hebei, and Inner Mongolia remain basically below 10. This situation shows that the overall development of China's construction industry is stable. The development of the construction industry has a strong geographical radiation effect. Beijing is one of the most stable regional construction industry gathering centers in China. To a certain extent, the attractiveness of the construction industry in Tianjin, Hebei, and Inner Mongolia has been suppressed.

China's construction industry network system is relatively stable in general. Beijing, Shanghai, Zhejiang, and Shaanxi have always occupied an important position in the space network system of China's construction industry by considering the industrial development level and geographical location of different provinces. They have become several large regional construction industry centers in China. The regional centers of the construction industry are mainly concentrated in the Beijing-Tianjin-Hebei urban agglomeration, the Yangtze River Delta urban agglomeration, the middle reaches of the Yangtze River urban agglomeration, and the Chengdu-Chongqing urban agglomeration according to the division of urban agglomerations in China.

\section{Measurement of the concentration level of China's construction industry}

This part uses spatial Gini coefficient, Moran's I index, and location entropy index to describe the concentration level of China's construction industry from local and overall perspectives . 
The analysis of spatial Gini coefficient and Moran index in the period of 2008-2019 reveals that the overall concentration of China's construction industry is at a medium level of $44 \%-60 \%$. The agglomeration of the construction industry has experienced a development process of decreasing first and then increasing. The agglomeration fell into a trough in 2011, peaked in 2019, and gradually entered a period of stable development. The regression analysis of the construction industry's Gini coefficient against time is conducted to further examine the change trend of the spatial agglomeration degree of China's construction industry, and a 5\% significance test is performed on the regression coefficient $(0.001)$ and the goodness-of-fit value (0.306). The geographical agglomeration of China's construction industry in the period of 2008-2019 shows an increasing trend, and the positive correlation of industrial space is constantly strengthened.

During the eleventh Five-Year Plan period, China's three major industrial restructuring has affected the development of the construction industry. The proportion of the primary and secondary industries decreased significantly. The rising proportion of the tertiary industry and the vigorous development of advanced manufacturing gradually decreased the agglomeration degree of China's construction industry from 2008 to 2011. In 2011, the Ministry of Housing and Urban-rural Development, together with the Jiangsu Provincial Department of Housing and Urban-rural Development, established the only "Green Building Industry Cluster Demonstration Zone" in Wujin to explore a new model for the development of the construction industry. The construction industry cluster demonstration area was further promoted to the whole country, which facilitated the rapid development of China's construction industry cluster level.

The four key node years of 2008 and 2019 are selected, and the Geoda software is used to analyze the dynamic change characteristics of the construction industry in various regions of China, as shown in Figure 2.
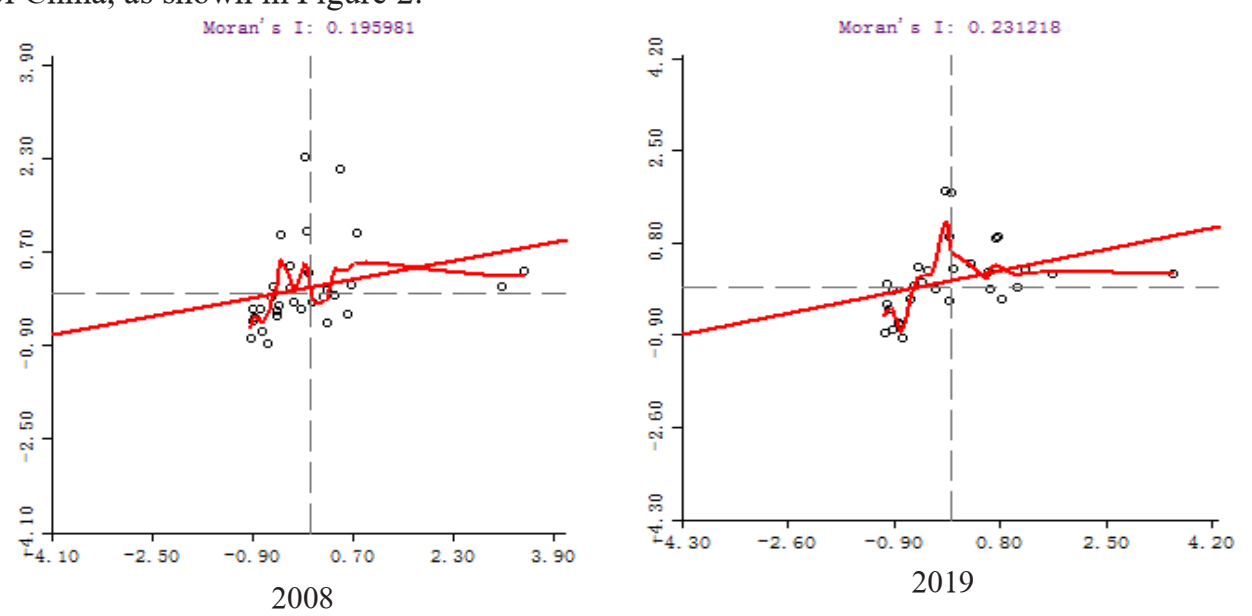

Fig. 2. Moran scatter plot of China's construction industry.

The analysis of the Moran scatter plot in Figure 4 indicates that the areas that fell in the first quadrant (high-high cluster area) before 2012 mainly include 6 provinces and cities, such as Beijing, Hebei, Shanghai, Jiangsu, Chongqing, and Zhejiang. Among them, Beijing and Shanghai, which are China's political and financial centers, have obvious advantages in the concentration of the construction industry. The concentration of construction industries in Jiangsu and Zhejiang has been rapidly improved because of Shanghai radiation. The Yangtze River Delta urban agglomeration with Shanghai as the center and the BeijingTianjin-Hebei urban agglomeration with Beijing as the center will surely become the main force of the "high-high-type agglomeration zone." 
Guizhou, Tibet, Guangxi, and other provinces are located in southwest China. The geographical location of these provinces is remote, and economic development is relatively backward. Therefore, the investment in the construction industry is obviously insufficient, and the lack of industrial investment seriously restricts the development of the regional economy and falls in the third quadrant (low-low-type agglomeration area). Provinces, such as Jiangxi and Anhui, are located in the Central Plains. Their attractiveness to industrial investment cannot be comparable to that of coastal cities, which results in a low density of the construction industry. This concept is consistent with the "distance theory and "economic theory" in the migration theory of British statistician Levinstein and thus forms the "central collapse" of the industry. However, after 2012, the areas that fell in the third quadrant of the Moran scatter plot decreased significantly, and a clear shift to the fourth quadrant (high-low isolated areas) was observed. This situation shows that the overall level of China's construction industry is constantly improving. In 2019, Gansu and Liaoning moved from low-high agglomeration areas to high-low agglomeration areas due to the influence of the surrounding cities and the strong support of the country.

In summary, the overall spatial agglomeration of China's construction industry appears to be centered on the Yangtze River Delta, Beijing-Tianjin-Hebei clusters, and the central and western urban agglomerations, such as the Central Plains urban agglomeration and the Guanzhong urban agglomeration.

The analysis of the location entropy index reveals that the location entropy index gap among China's regions is large, and the overall agglomeration level is low. From 2008 to 2019, the location entropy index of the construction industry in Beijing, Tianjin, Shanghai, Jiangsu, Zhejiang, and Guangdong and other eastern coastal areas was greater than 1, which indicates a high regional agglomeration phenomenon. The location quotient index of the construction industry in western provinces is generally low. However, construction resources are flowing from the eastern region to the western region at an accelerated pace due to the implementation of national strategies, such as "western development" and "One Belt And One Road." This situation drives the development of the construction industry in the western region. The location entropy index presents an obvious rising trend.

The spatial Gini coefficient of Liaoning, Xizang, and Xinjiang is less than 0.1 or even close to 0 because of geographical location restriction. This value implies extremely weak spatial agglomeration. This conclusion is consistent with the conclusion of spatial Gini coefficient analysis.

\section{Analysis of the characteristics of space-time deduction of the agglomeration and development of China's construction industry}

This part selects relevant data from 2008 to 2019 to conduct spatiotemporal deductive characteristics analysis of China's construction industry from two dimensions of time and space through annual growth rate of location entropy and spatial autocorrelation for predicting the agglomeration development direction of this industry.

\subsection{Time deduction feature analysis}

In recent years, the construction industry agglomeration pattern is changing constantly with the deepening of China's construction industry. This part is based on the overall location quotient index of the construction industry in 31 provinces of China from 2008 to 2019. The average annual growth rate of the location quotient index of each province is calculated, and the development speed and time deduction characteristics of the construction industry agglomeration level in China are analyzed. The Equation is shown below: 


$$
m=\left(\sqrt[n-1]{\frac{B}{A}-1}\right) \times 100 \%,
$$

where B is the location entropy index of the construction industry in 2019; A is the location entropy index of the construction industry in 2008; $\mathrm{N}$ is the total number of years in the study interval, 12 years. The calculation results are shown in Table 4.

Table 2. Average annual growth rate of the total location quotient index of China's construction industry.

\begin{tabular}{cccc|lccc}
\hline Provinces & 2008 & 2019 & $\begin{array}{c}\text { Average } \\
\text { annual } \\
\text { growth rate }\end{array}$ & Provinces & 2008 & 2019 & $\begin{array}{c}\text { Average } \\
\text { annual } \\
\text { growth rate }\end{array}$ \\
\hline $\begin{array}{c}\text { Heilongjiang } \\
\text { Xinjiang }\end{array}$ & 0.15 & 0.89 & 12.48 & Guizhou & 1.18 & 0.73 & -5.91 \\
Shanxi & 0.79 & 1.37 & 3.80 & Guangxi & 0.51 & 0.84 & 6.41 \\
Ningxia & 1.41 & 1.13 & -2.67 & Guangdong & 0.82 & 1.12 & 3.95 \\
Xizang & 0.73 & 0.80 & 1.15 & Hainan & 0.34 & 0.84 & 11.86 \\
Shandong & 0.69 & 0.58 & -2.11 & Jilin & 0.62 & 0.48 & -3.14 \\
Henan & 0.44 & 0.66 & 5.32 & Liaoning & 0.72 & 0.20 & -14.77 \\
Jiangsu & 0.84 & 1.04 & 2.73 & Tianjin & 1.12 & 1.02 & -1.15 \\
Anhui & 0.56 & 0.61 & 1.10 & Qinghai & 1.06 & 0.90 & -2.04 \\
Hubei & 0.50 & 0.55 & 1.06 & Gansu & 0.62 & 0.89 & 4.59 \\
Zhejiang & 1.45 & 0.87 & -6.14 & Shaanxi & 0.67 & 0.89 & 3.68 \\
Jiangxi & 0.44 & 0.85 & 5.04 & Neimenggu & 0.44 & 0.56 & 3.16 \\
Hunan & 0.53 & 0.45 & -2.09 & Chongqing & 0.73 & 1.24 & 6.84 \\
Yunnan & 1.05 & 1.05 & -0.05 & Hebei & 0.56 & 0.70 & 2.78 \\
Beijing & 3.78 & 2.32 & 6.84 & Shanghai & 2.34 & 2.45 & 0.58 \\
Sichuan & 1.20 & 0.80 & -4.97 & & & & \\
\hline
\end{tabular}

Table 2 shows that the annual growth rate of location entropy index of China's construction industry is in a state of rapid growth. Among the values, the location entropy index of Heilongjiang was 0.15 in 2008, which is the lowest level in China; however, it reached 0.39 in 2019 and had an annual growth rate of $12.48 \%$. Hainan relies on its superior geographical position. It also maintains a fast development speed because of the drive from other coastal cities, and its construction industry has an obvious tendency of agglomeration. With the implementation of the policies of "western development" and "One Belt And One Road," the location quotient index of Chongqing and Shanxi construction industry soared rapidly. Thus, the evolution from non-agglomeration state to agglomeration state was realized. The integration of Beijing, Tianjin, and Hebei has effectively promoted the agglomeration of the construction industry around Beijing, and the average annual growth rate of location entropy is as high as $6.84 \%$. Although the construction industry in Tibet has not formed an obvious agglomeration trend, it has a relatively high average annual growth rate and will have the opportunity to form an agglomeration development pattern. Provinces with a negative annual growth rate of location entropy index include Ningxia, Xinjiang, Shandong, Zhejiang, Hunan, Sichuan, Guizhou, Jilin, Liaoning, Tianjin and Qinghai. However, the construction industry in these provinces is not completely in a state of agglomeration, and Zhejiang and Tianjin have always maintained the state of industry agglomeration. However, Tianjin is close to Beijing. Beijing, which is the capital city, has 
the optimal industrial resources and gathers a large number of high-quality resources and institutions. The city not only drives the development of the construction industry in neighboring Tianjin and Hebei provinces but also restricts the improvement in the concentration level of the construction industry in neighboring provinces. As the eastern coastal province that takes the lead in development, Zhejiang has unique location advantage and advanced industrial structure. The development of its construction industry also started earlier. The radiation effect on the surrounding provinces reduced the concentration level of its own construction industry, but the neighboring provinces, such as Jiangsu, maintained a relatively fast growth rate. The clustering location entropy index of the construction industry in Guizhou declines rapidly. It evolved from the state of building agglomeration to nonagglomeration, which mainly originated from the hilly basin of Guizhou Province. Therefore, industrial economic development is limited.

\subsection{Analysis of the spatial deductive characteristics of agglomeration and development of the construction industry}

According to the abovementioned analysis, most provinces with the same level of regional entropy are similar in geographical location, and the inter-provincial construction resources flow smoothly. For example, Hebei has a high level of construction industry agglomeration under the influence of the capital Beijing. The average concentration of construction industries in eastern coastal areas, such as Jiangsu, Fujian, and Guangdong, is relatively high because of the drive from Shanghai. In order to grasp the spatial deduction path and specific characteristics of China's construction industry in 31 provinces more comprehensively, this part analyzes the global spatial correlation and local spatial correlation of China's construction industry.

\subsubsection{Global spatial correlation analysis of construction industry agglomeration level}

The purpose of spatial correlation analysis is to determine whether certain individuals or events are spatially related and how relevant they are. Spatial weight matrix is an important tool to quantify the degree of interdependence and correlation among individuals. It is used to analyze the influence relationship and radiation degree among different spatial units and is usually expressed as an n-order non-negative matrix. The specific form is as follows:

$$
W=\left[\begin{array}{ccc}
\mathcal{W}_{11} & \cdots & \mathcal{W}_{1 n} \\
\cdots & \cdots & \cdots \\
\mathcal{W}_{n 1} & \cdots & \mathcal{W}_{n n}
\end{array}\right],
$$

where $\mathrm{n}$ is the number of spatial units, which means that the 31 provincial regions of China are taken as the research objects; Wij represents the spatial interaction between region I and region J. A larger weight value Wij corresponds to a greater the spatial dependence between the two regions. When used, it is usually standardized as follows to reduce or eliminate the external influence between regions.

According to the test results, the Moran's I index of the overall location entropy of the construction industry from 2008 to 2019 is positive. Except for 2014, 2015, and 2018, which were significant at a significance level greater than 0.05 , all other years passed the test at a significance level of 0.05 . This result indicates that a significant spatial positive correlation exists among the construction industry agglomeration levels of various provinces in China. Provinces with higher level of construction industry cluster tend to be adjacent to other provinces with higher level of cluster, while provinces with lower level of cluster tend to be 
adjacent to other provinces with lower level of cluster. In addition, the continuous increase in the Moran index indicates that the provinces with a high level of China's construction industry agglomeration from 2008 to 2019 have driven the development of the construction industry in the neighboring areas, and the construction industry agglomeration areas are gradually concentrated. Since then, the vigorous development of Internet architecture and the increasing diversity of construction resources in various provinces have gradually weakened the spatial dependence of the concentration level of the construction industry. The agglomeration areas are increasingly dispersed geographically.

\subsubsection{Local spatial correlation analysis of construction industry concentration level}

The global Moran's I index can reflect the overall spatial correlation of China's construction industry agglomeration but cannot reflect the spatial correlation between specific provinces. In consideration of the abovementioned defects, LISA statistics and cluster maps are used to test the local spatial correlation tools to comprehensively analyze the local spatial correlation characteristics of the construction industry among various provinces in China.

According to the significance test results of LISA statistics and Figure 3, 10, 7, 8, and 12 provinces passed the significance test in 2008 and 2019. The correlation spatial correlation analysis results are consistent. In 2008, Tianjin and Shanghai were the only provinces in the first quadrant that passed the test at a significant level of 0.1 , which shows a "high-high" agglomeration. The provinces in the third quadrant passed the test at the significance level of 0.1 in Fujian, Hainan, and Guangdong, which shows "low and low" agglomeration; the statistic statistics of other provinces were insignificant. In 2012 and 2016, Jiangsu, Zhejiang, and Shanghai in the first quadrant passed the test at the significance level of 0.1 , which represents a "high-high" agglomeration. Among the provinces in the second quadrant, Xinjiang passed the test at the significance level of 0.1 , which represents "high and low" clustering. Among the provinces in the fourth quadrant, Jiangxi passed the test at the significance level of 0.1 , which indicates "low and high" clustering; LISA statistics in other provinces were insignificant. In 2019, Shanghai is the only province in the first quadrant to pass the test at the significance level of 0.1, which implies a "high-high" agglomeration. Among the provinces in the third quadrant, Guangdong and Hainan passed the test at the significance level of 0.1 , which denotes "low" clustering. Among the provinces in the fourth quadrant, Ningxia passed the test at the significance level of 0.1 , which implies "low and high" clustering; LISA statistics in other provinces were insignificant.

The location entropy index of the construction industry in Northeast China has always been in an insignificant state of aggregation. The three northeastern provinces, as China's old industrial bases, focus on the development of agriculture, energy, and heavy industry, with a solid industrial foundation and a relatively high proportion of state-owned enterprises. Although the country implements the strategy of northeast revitalization, the deep-rooted original economic system decreases the effect, slows down the industrial development, and decreases the degree of agglomeration. The provinces in southern China, such as Guangdong, show a significant "low-low" agglomeration, which is consistent with the conclusion that the overall construction industry agglomeration level in southern China is low. Among them, Shanxi's construction industry agglomeration level has gradually improved and showed a significant "high" agglomeration after 2016. The eastern region has a deep economic foundation and good geographical advantages. It has formed the Bohai Rim financial circle centered on Beijing and Tianjin. The construction concentration in the eastern region has increased substantially because of the drive from the aforementioned provinces. Guangdong shows a "low-low" agglomeration state from 2008 to 2019, but the agglomeration index is rising. On the one hand, Guangdong's construction industry has gradually developed from low-level agglomeration to high-level agglomeration. On the other hand, Guangdong is 
surrounded by central and western provinces. The construction industry in these provinces has developed relatively slowly, and the level of construction industry agglomeration is relatively low. Among the location entropy index values of the western regions, only that of Ningxia's construction industry showed a significant "low-high" concentration. Therefore, the agglomeration level of the two provinces is low, while the agglomeration level of the construction industry in the surrounding provinces is high. The construction industry clusters in other western provinces have not shown a significant regional association.
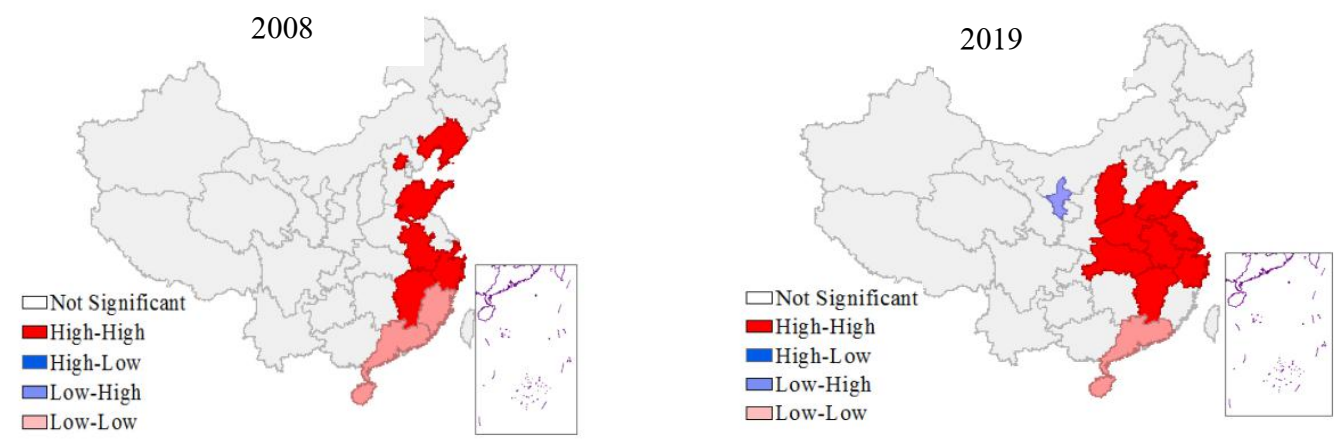

Fig. 3. LISA agglomeration map of the overall location entropy index of the Chinese construction industry.

\section{Conclusion}

Gravity model and social network analysis show that the spatial structure of China's construction industry is gradually becoming clear. The spatial agglomeration and development pattern of the construction industry with Beijing, Shanghai, Zhejiang, and Shaanxi as the centers has been formed. Spatial Gini index and Moran index measurement results are consistent. The results show that the construction industry concentration in eastern China is the highest, while that in central China, South China, and Northeast China is relatively low. The analysis of spatiotemporal evolution characteristics shows that, except for the concentration level of the construction industry in the central and eastern regions, that in most regions of China presents an upward trend. However, the rising speed is quite different.

From the perspective of spatial deduction characteristics, the agglomeration level of construction industry in all provinces has significant positive spatial correlation. Most provinces with significant local correlation feature show "low-low" clustering characteristics. This situation reflects the low overall clustering level of China's construction industry from the side.

With the investment focus shifting from the coast to the inland of the central and western regions, the "group center" has become the spatial development strategy and has gradually developed into a multi-center, open, and networked industrial system complex. This situation will free up space for the balanced development of the construction industry. The imbalance in the agglomeration of the construction industry in urban agglomerations is gradually weakened.

This work is supported by the Beijing Municipal Natural Science Foundation (No. 9202006) the Excellent Talent Project of North China University of Technology in 2019 (No. $216051360020 \mathrm{XN} 225 / 004)$ and Research on the evaluation index system of industrial building development level (No. 2016YFC0701808-02). 


\section{References}

1. He Canfei, Pan Fenghua, Sun Lei. Geographical concentration of manufacturing industries in China. J. Acta Geographica Sinica, 2007, 62(12), 1253-1264.

2. Fan C C, Scott A J. Industrial agglomeration and development: A survey of spatial economic issues in east Asia and a statistical analysis of Chinese regions. J. Economic Geography, 2003, 79(3), 295-319.

3. Zhou Shengqiang, Zhu Weiping. Must industrial agglomeration be able to bring about economic efficiency: Economies of scale and crowding effect. J. Industrial Economics Research, 2013, 3, 12-22.

4. Wang Kai, Yi Jing, Xiao Yan, et al. The correlation between tourism agglomeration and industrial efficiency in China. J. Human geography, 2016, 31(2), 120-127.

5. Shi Yanwen, Li Erling, Li Xiaojian, et al. The agricultural industry cluster innovation network and knowledge flow based on SNA: The cases of Shouguang vegetable cluster and Yanling flower and plant cluster. J. Economic Geography, 2015, 35(8), 114-122.

6. Li Erling, Shi Yanwen, Li Xiaojian. The structure analysis of agricultural innovation system based on agricultural cluster: A case study of flower and plant industrial cluster in Yanling County, Henan Province. J. Economic Geography, 2012, 32(11), 113-119.

7. Liu Chao, Li Dalong. Research on the motivation of financial industry agglomeration evolution based on complexity theory . J. Contemporary Economic Research, 2013, 10, 55-62.

8. Qin Tai, Xu Shen. An empirical analysis of the trend of financial agglomeration. $J$. Journal of Chongqing University of Science and Technology (Social Science Edition), 2012, $1,80-83$.

9. Marshall A. Principles of Economics, 8th ed; London: Macmillan, 1920; pp. 154 160.

10. Paul Krugman. Geography and Trade; Translated by Zhang Zhaojie, Beijing: Peking University Press, Renmin University Press, 2000.

11. Fan Xiufeng, Kang Xiaoqin. Agglomeration level measurement of manufacturing in Shaanxi Province and its influencing factors empirical analysis. J. Economic Geography, 2013, 33(09), 115-119+160.

12. Pan Wenqing, Liu Qing. The manufacture industries agglomeration and the regional economic growth in China: Based on China's industrial enterprises database. J. Journal of Tsinghua University (Philosophy and Social Sciences Edition), 2012, 1, 137-147.

13. Wen Dongwei, Xian Guoming. The degree of China's manufacturing industry agglomeration and its evolution trend: 1998-2009. J. The Journal of World Economy, 2014, 3, 3-31.

14. Yang Shouyun, Zhao Xin, Wang Yiqiao. The Impact of high-tech industry agglomeration on industrial efficiency - An empirical test based on Williamson hypothesis and openness hypothesis. J. Science and Technology Progress and Policy, 2019, 36(20), 69-76.

15. Melitz M J. The impact of trade on intra-industry reallocations and aggregate industry productivity. J. Econometrica, 2003, 71(6), 1695-1725.

16. Bernard, Andrew, B. Plants and productivity in international trade. J. American Economic Review, 2003, 93(4), 1268-1290. 
17. Melitz M J, Ottaviano G I P. Market size, trade, and productivity. J. Review of Economic Studies, 2008, 75(1), 295-316.

18. Greenaway D, Kneller R. Exporting, productivity, and agglomeration. J. European Economic Review, 2008, 52(5), 0-939.

19. Clerides S K, Saul L, Tybout J R. Is learning by exporting important? Microdynamic evidence from Colombia, Mexico, and Morocco*. J. Quarterly Journal of Economics, 1998, 113(3), 903-947.

20. Zhao Tingting, Xu Mengbo. The mechanism and effect of industrial agglomeration affecting regional innovation - An empirical test based on China provincial panel data. J. Scientific Management Research, 2020, 38(01), 83-88.

21. Zhao Qingxia, Xia Chuanxin, Shi Jianjun. Sci-tech talents agglomeration, industry agglomeration, and regional innovation capability: Empirical analysis based on JingJin-Ji Region, Yangtze River Delta, and Pearl River Delta. J. Science and Technology Management Research, 2019, 39(24), 54-62.

22. Dijk M P V, Soltan S. Palestinian clusters: From agglomeration to innovation. $J$. European Scientific Journal, 2017, 13(13), 323-336.

23. Chen Qiangqiang, Ye Deming. Spatial pattern of animal husbandry industrial agglomeration in Gansu Province. J. Arid Land Geography, 2018, 41(03), 652-660.

24. Chen Qiangqiang, Tang Zhengxing, Li Guoshun. Spatial agglomeration and the driving factors of traditional Chinese medicine industry in Gansu Province. J. Research of Agricultural Modernization, 2017, 38(01), 145-153.

25. Ji Zhenglong, Song Yu. Design and application of central gravity index algorithm for industrial spatial agglomeration: Enterprise micro data verification based on the integration perspective of the Yangtze River Delta. J. Statistics and Information Forum, 2020, 35(03), 38-48.

26. Luo Yinchen, Gu Renxu. The pattern and evolutional trend of Chinese manufacturing's spatial agglomeration - An empirical analysis based on data from 1980 to 2011. J. Economic Geography, 2014, 34(07), 82-89.

27. He Canfei, Pan Fenghua. The trends of geographical agglomeration of manufacturing sectors in China and the explanations. J. South China Journal of Economics, 2011, 06, 38-52.

28. He Canfei, Xie Xiuzhen. Geographical concentration and provincial specialization of Chinese manufacturing industries. J. Acta Geographica Sinica, 2006, 02, 212-222.

29. Bi Xuecheng, Gu Renxu, Su Qin, Lin Shanquan. The agglomeration of manufacturing industry and the evolution of geographical pattern in Jiangsu Province. $J$. East China Economic Management, 2018, 32(07), 12-21.

30. Zheng Xiao, Liu Zhenning. Thoughts on the Gini Coefficient and Industrial Agglomeration Development of the Construction Industry in Eight Southeastern Provinces [A]. Scientific Research Publishing, USA. Proceedings of the 2010 International Conference on Information Technology and Scientific Management (Volume 2) [C]. Scientific Research Publishing, USA: 2010:6.

31. Liu Bingsheng, Xue Bin. Analysis of the three-dimensional system of industry linkages with spatial difference for the Chinese regional construction industry. J. Journal of Chongqing University (Social Science Edition), 2015, 21(01), 16-22.

32. Liu Bingsheng, Chen Xiaohong, Xue Bin, Fang Ning. Research on gradient changes and influential mechanism of development level in Chinese regional construction industry. J. Operations Research and Management Science, 2016, 25(01), 254-261. 
33. Ma Hui, Wang Suzhen, Huang Mengjiao. Analysis of factors influencing cooperative innovation in construction industry alliance based on social network analysis: Taking Beijing-Tianjin-Hebei Region as an example. J. Science and Technology Management Research, 2018, 38(15), 170-176.

34. Zhang Mao, Qiao Dongyan, Dai Yongan. A spatial econometric analysis of the construction's differences in China's provincial regions. J. Scientific Decision Making, 2010, 03, 87-93.

35. Dai Yongan, Chen Cai. Spatial econometric analysis of regional differences in China's construction industry development. J. Statistics and Information Forum, 2010, 05, 53-58.

36. Bu Weiwei, Zhou Wei, Li Wanting. Correlation analysis of provincial construction industry development based on factor analysis. J. Journal of Civil Engineering and Management, 2019, 36(02), 127-131+145. 